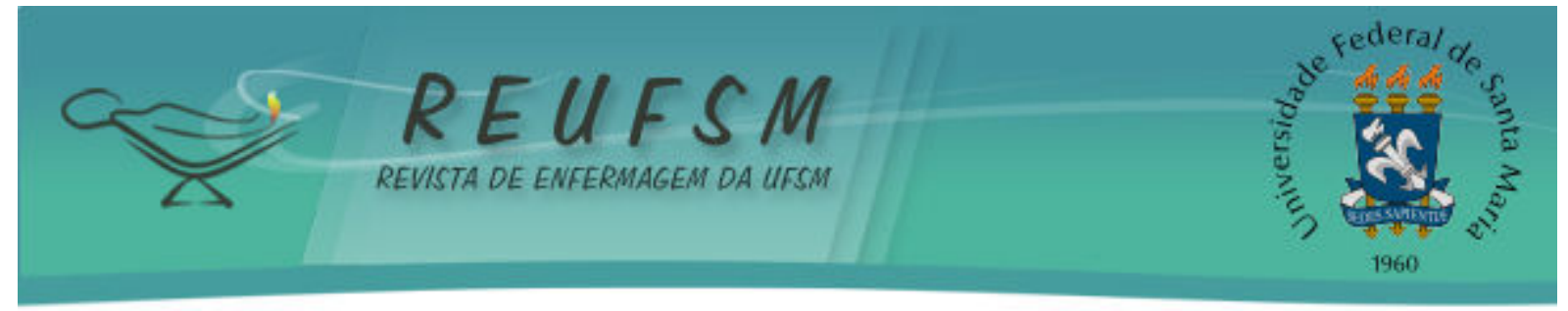

ARTIGO ORIGINAL

\title{
TECENDO PRÁTICAS INTERSETORIAIS EM SAÚDE MENTAL PARA PESSOAS EM SOFRIMENTO PSÍQUICO
}

CONSTRUCTING INTER-SECTOR PRACTICES IN MENTAL HEALTH FOR PEOPLE IN PSYCHIC SUFFERING

\section{TEJIENDO PRÁCTICAS INTERSECTORIALES EN SALUD MENTAL PARA PERSONAS EN SUFRIMIENTO PSÍQUICO}

Doi: $10.5902 / 2179769213562$

Elisângela Braga de Azevedo ${ }^{1}$

Rafael Nicolau Carvalho

Renata Cavalcanti Cordeiro ${ }^{3}$

Lorena de Farias Pimentel Costa ${ }^{4}$

Priscilla Maria de Castro Silva ${ }^{5}$

Maria de Oliveira Ferreira Filha ${ }^{6}$

RESUMO: Objetivo: conhecer as práticas intersetoriais de inclusão social desenvolvidas na rede de cuidado em saúde mental para pessoas em situação de sofrimento psíquico do município de Campina Grande/Paraíba/Brasil. Método: pesquisa qualitativa, exploratória e descritiva realizada com quatro profissionais por meio de entrevista semiestruturada, gravada, no período de junho a julho de 2010. O material produzido foi submetido à análise de conteúdo proposta por Bardin. Resultados: o discurso da Reforma Psiquiátrica em direção à desinstitucionalização, a inclusão social e a conquista da cidadania têm induzido os profissionais que atuam nos serviços substitutivos irem à busca de parceiros intersetoriais, tais como: Serviço Nacional de Aprendizagem Industrial (SENAI), Centro de Convivência e Cultura, Centro Jovem Cidadão e Centro de Referência da Assistência Social (CRAS). Conclusão: práticas inclusivas se constituem como estratégias eficazes para reabilitação psicossocial e contribuem para o desenvolvimento de políticas públicas e para integralidade do cuidado relacionado à saúde mental.

Descritores: Saúde mental; Serviços de saúde mental; Mudança social; Enfermagem.

\footnotetext{
*Este artigo é uma reelaboração parcial da dissertação de Mestrado, intitulada: Rede de Cuidado em Saúde Mental: Tecendo Práticas de Inclusão Social no município de Campina Grande, PB. Vinculado ao Programa de Pós-Graduação em Enfermagem da Universidade da Paraíba - UFPB.

1 Enfermeira. Doutoranda em Enfermagem pelo Programa de Pós-Graduação da Universidade Federal da Paraíba. Professora do Departamento de Enfermagem da Faculdade de Ciências Médicas. João Pessoa (PB). Brasil. Campina Grande/Paraíba/Brasil. E-mail: elisaaz@terra.com.br.

2 Assistente Social, Doutorando em Sociologia. Professor Assistente do Departamento de Serviço Social da Universidade Federal da Paraíba. Preceptor da Residência Multiprofissional em Saúde da Família e Comunidade. Coordenador do PET Saúde Mental/2011 - UFPB, João Pessoa/Paraíba/Brasil. E-mail: rafaelcg_carvalho@yahoo.com.br

${ }^{3}$ Enfermeira. Mestre em Enfermagem pelo Programa de Pós-Graduação da Universidade Federal da Paraíba. Campina Grande/Paraíba/Brasil E-mail: renatacc@outlook.com

${ }^{4}$ Enfermeira. Doutoranda do Programa de Pós-Graduação em Enfermagem da Universidade Federal da Paraíba. Campina Grande/Paraíba/Brasil. E- mail: lorenafarias@outlook.com

5 Enfermeira. Doutoranda do Programa de Pós-Graduação em Enfermagem da Universidade Federal da Paraíba. Professora do Departamento de Enfermagem da Universidade Federal de Campina Grande - PB. Campina Grande/Paraíba/Brasil. E-mail: priscillamcs@hotmail.com

6 Enfermeira. Doutora em Enfermagem pela Universidade Federal do Ceará. Professora da Universidade Federal da Paraíba. Líder do Grupo de Estudos e Pesquisas em Saúde Mental Comunitária da UFPB. João Pessoa/Paraíba/Brasil. E-mail: marfilha@yahoo.com.br
} 


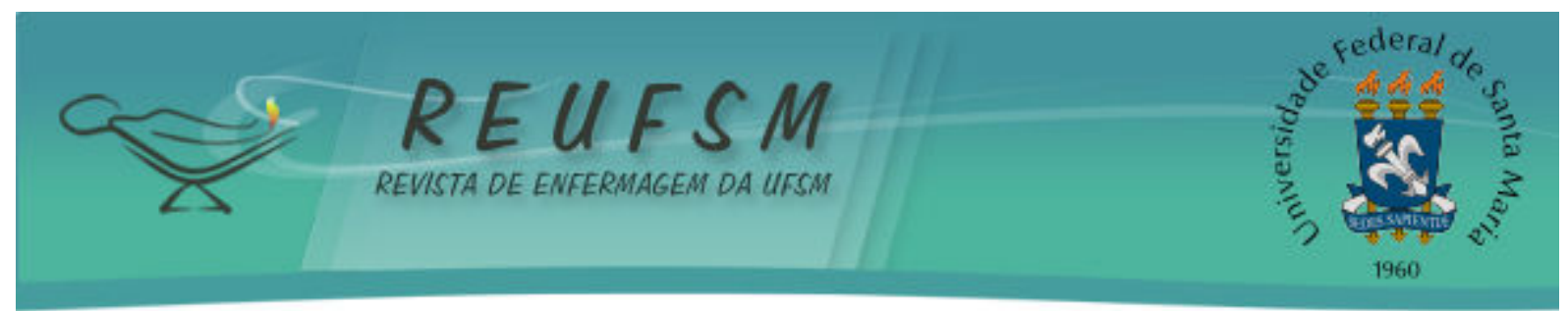

ABSTRACT: Objective: to understand the inter-sector practices of social inclusion developed in the mental health care network to people in psychic suffering, in the municipality of Campina Grande/Paraíba/Brazil. Method: a qualitative, exploratory and descriptive research conducted with four professionals through semi-structured interviews, recorded from June to July 2010. The produced material was analyzed through content analysis, proposed by Bardin. Results: the Psychiatric Reform discourse towards deinstitutionalization, social inclusion and achievement of citizenship has impelled professionals working in substitute services to seek inter-sector partners, such as: National Service for Industrial Training (SENAI), Culture and Living Center, Young Citizen Center and Reference Centers for Social Assistance (CRAS). Conclusion: inclusive practices are effective strategies for psychosocial rehabilitation and contribute to the development of public policies and comprehensiveness of mental health care.

Descriptors: Mental health; Mental health services; Social change, Nursing.

RESUMEN: Objetivo: conocer las prácticas intersectoriales de inclusión social desarrolladas en la red de atención a la salud mental de Campina Grande (Paraíba, Brasil). Método: investigación cualitativa, exploratoria y descriptiva dirigida por cuatro profesionales, mediante entrevista semi-estructurada, grabada entre junio y julio de 2010. El material producido fue analizado mediante análisis de contenido propuesto por Bardin. Resultados: el discurso de la Reforma Psiquiátrica hacia la desinstitucionalización, la inclusión social y la conquista de la ciudadanía han inducido a los profesionales que trabajan en los servicios sustitutivos a buscar socios intersectoriales, tales como: Servicio Nacional de Aprendizaje Industrial (SENAI), Centro Convivencia y Cultura, Centro Joven Ciudadano y Centro de Referencia de Asistencia Social (CRAS). Conclusión: prácticas inclusivas se constituyen como estrategias eficaces para la rehabilitación psicosocial y contribuyen al desarrollo de políticas públicas y a la integralidad de la atención relacionada con salud mental.

Descriptores: Salud mental; Servicios de salud mental; Cambio social; Enfermería.

\section{INTRODUÇÃO}

A implementação do Sistema Único de Saúde (SUS) e o processo de construção da Reforma Psiquiátrica Brasileira tem estabelecido consistentes mudanças no âmbito das políticas públicas e das instituições de saúde mental do país, tendo como horizonte o paradigma da integralidade da atenção em saúde, da intersetorialidade, que se desdobram na atual configuração das redes de cuidado, e no caso específico da Saúde Mental, a Rede de Atenção Psicossocial (RAPS) ${ }^{1}$.

A criação da RAPS, por meio da portaria ministerial, estabelece os pontos de atenção às pessoas em sofrimento psíquico, refere-se à oferta de diversos serviços em rede, tem por princípio estruturante aprofundar a perspectiva da desinstitucionalização, que consiste na ampliação de serviço de saúde mental em base territorial e comunitária, que articule diversos segmentos sociais de modo a se afastar do modelo manicomial centrado na exclusão do usuário e de sua família do contexto social. Tal perspectiva reforça ainda o conceito de inclusão social, entendido como toda tentativa de resgatar a cidadania dos seus usuários, seja através do acolhimento, da assistência, do resgate ao convívio social, familiar e na sociedade. ${ }^{1-2}$

Portanto, percebe-se que a intersetorialidade, a integralidade, presente na concepção de redes de cuidado, reforçam os princípios fundamentais da Reforma Psiquiátrica Brasileira, e da atual política de saúde mental, a desinstitucionalização e a inclusão social de seus usuários. 


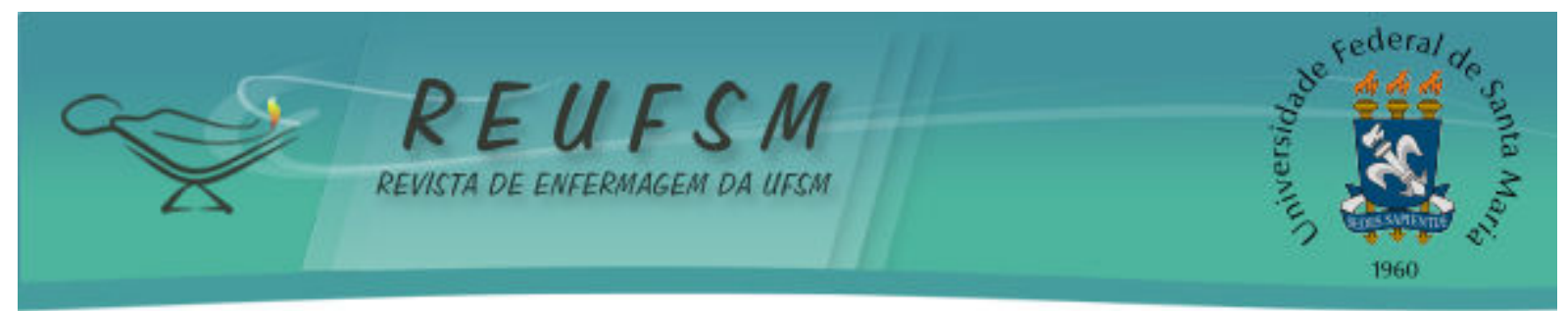

No entanto, para melhor compreensão, cabe reconstruir os processos formativos desses arranjos a partir dos preceitos sócio-históricos do que se constitui o movimento de Reforma Psiquiátrica, que emergiu na década de 1970, em plena ditadura militar, tendo sido caracterizado por um cenário de repressão, punições e agressões. ${ }^{1}$

No lastro do movimento sanitário, a Reforma Psiquiátrica contribuiu com a crítica ao modelo hospitalocêntrico e biomédico, possibilitando a busca pela redemocratização do país baseada num processo complexo que abrange quatro dimensões: dimensão epistemológica; técnico-assistencial, política e sociocultural. ${ }^{3}$

A dimensão técnico-assistencial refere-se aos modelos de atenção a saúde, às práticas profissionais e a organização dos serviços a partir dos princípios do cuidado. Implica uma intersecção entre teoria e prática na construção de novos modelos de intervenção pautados em estratégias como a intersetorialidade, a inclusão social, a geração de renda, dentre outros. ${ }^{3}$

A dimensão política refere-se ao protagonismo social na construção de políticas públicas, da emergência de movimentos que se encontram na base do processo de pactuação intergestores para a reivindicação/construção dos direitos sociais. ${ }^{3}$

A dimensão sociocultural refere-se aos processos sociais e culturais para desconstrução do preconceito e do estigma que fazem parte do imaginário social sobre a loucura. Assume o desafio de transformar o conhecimento e práticas em um "senso comum emancipatório" capaz de minimizar o preconceito social das pessoas em sofrimento mental. ${ }^{3}$

Paradoxalmente, os movimentos sociais que emergiam das grandes periferias urbanas datam dessa conjuntura, quando as reivindicações eram sobre as necessidades de sobrevivência da população. A Reforma Sanitária Brasileira avançou nas lutas pela garantia dos direitos a saúde e a cidadania, a partir da construção de novos sujeitos, inseridos no coletivo devido a interesses comuns. ${ }^{4-5}$

Nesse ínterim, a inclusão social tornou-se um dos maiores desafios da Reforma Psiquiátrica, tendo em vista que no Brasil o processo de exclusão social está fortemente associado às heranças culturais, políticas e sociais, procedentes de uma sociedade em que a negociação dos conflitos tem sido historicamente substituída pelo autoritarismo, pela omissão e a negligência. ${ }^{6}$

Por sua vez, a expressão dos direitos humanos assume na saúde mental um sentido singular, por tratar-se de uma luta pela inclusão de novos sujeitos e de novos direitos para aqueles que vivem em sofrimento psíquico. Tal luta perpassa pelo direito ao trabalho, ao estudo, ao lazer, ao esporte, a cultura, bem como a todos os recursos que a sociedade oferece. ${ }^{7}$

Os Centros de Atenção Psicossocial (CAPS) tornaram-se os principais serviços substitutivos a partir da Reforma Psiquiátrica, possibilitando o desenvolvimento de atividades extramuros, atuando como parte integrante das estratégias terapêuticas de reabilitação psicossocial a partir da articulação com a comunidade, o trabalho e a vida social. ${ }^{7}$ Assim, cabe enfocar que a assistência oferecida nos serviços dispostos na rede de saúde mental necessita realizar articulação entre clínica e programas de reabilitação e inserção social por meio de ações que favoreçam a intersetorialidade. ${ }^{8}$

A intersetorialidade, como meio de atuação profissional, trata da articulação entre sujeitos de setores sociais diversos e, portanto, de saberes, poderes e vontades que visem enfrentar problemas complexos. Como possibilidade para gestão torna-se uma forma de construir políticas públicas que pretendam possibilitar a superação da fragmentação dos conhecimentos e das estruturas sociais para produzir efeitos mais significativos na saúde da população. ${ }^{9}$ Desse modo, entende-se que a ação intersetorial necessita ser construída 


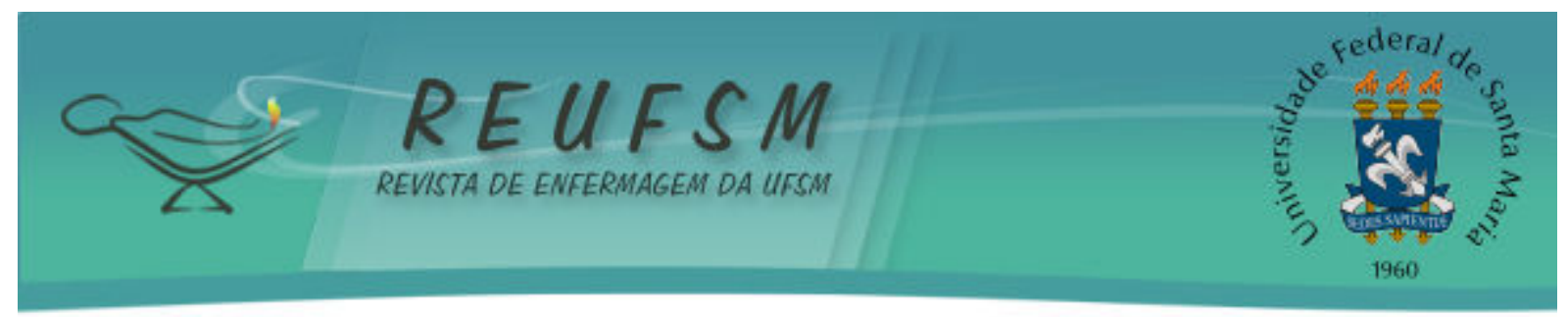

sob situações concretas no que diz respeito ao estilo de vida das pessoas, pois são elas que criam o espaço possível de interação e ação. ${ }^{10}$

Neste contexto, justifica-se a importância desta pesquisa, uma vez que investigar as possíveis práticas de inclusão social na rede de cuidado a saúde mental representa um elemento primordial no paradigma da reforma psiquiátrica adotada no país e por se tratar de uma temática ora tão desafiadora no campo da saúde mental. Acredita-se que a divulgação de tais práticas poderá contribuir para a divulgação de resultados promissores que possam ser desenvolvidos em diferentes contextos.

Assim, este estudo remete-nos a um questionamento: Como a rede de atenção a saúde mental está tecendo práticas intersetoriais de cuidado para promover a inclusão social para as pessoas em situação de sofrimento psíquico?

Nessa perspectiva, objetivou-se conhecer as práticas intersetoriais de inclusão social, desenvolvidas na rede de cuidado em saúde mental para pessoas em situação de sofrimento psíquico do município de Campina Grande/ Paraíba (PB)/ Brasil.

\section{MÉTODO}

Trata-se de uma pesquisa exploratória e descritiva que teve a abordagem qualitativa como orientadora do recorte do objeto e das análises teórico-empíricas, considerando que o seu objeto envolve a subjetividade de um grupo social. ${ }^{11}$

A pesquisa foi desenvolvida no município de Campina Grande/PB/Brasil, na rede de atenção à saúde mental: CAPS I; CAPS II; CAPS III; CAPS infantil (CAPSi) CAPS álcool e drogas (CAPS ad) e um Serviço Residencial Terapêutico (SRT), escolhido intencionalmente. As entrevistas aconteceram nos serviços onde os profissionais estavam lotados. Participaram desse estudo 19 profissionais, sendo, quatro enfermeiros, três Assistentes Sociais, sete Psicólogos, quatro fisioterapeutas e um (01) técnico de enfermagem, desses, apenas dois, eram do sexo masculino e dezessete do feminino, com idades entre vinte e cinco e quarenta e cinco anos.

Foram utilizados os seguintes critérios de inclusão: profissionais que atuam por um período mínimo de um ano na rede de saúde mental do município e desenvolvem práticas de inclusão social de caráter intersetorial. Após delimitação dos profissionais procedeu à assinatura do Termo de Consentimento Livre e Esclarecido (TCLE) e posterior entrevista.

Para tanto, foi utilizado como instrumento de coleta do material empírico, um roteiro de entrevista semiestruturada, gravada em aparelho digital, que ocorreu no mês de junho a julho de 2010, realizada no serviço onde o profissional estava atuando. Como critério para entrevista desses profissionais respeitaram-se os critérios de inclusão supracitados, os horários e locais pré-estabelecidos pelos participantes. As entrevistas foram finalizadas em julho de 2010 após todos os profissionais eleitos para participarem da pesquisa serem entrevistados. 0 questionamento central que norteou as entrevistas foi: Quais práticas que favorecem a intersetorialidade e consequentemente a inclusão social das pessoas em situação de sofrimento psíquico, estão sendo desenvolvidas por você aqui neste serviço?

Posteriormente, as entrevistas foram transcritas na íntegra e de forma literal pela (o) pesquisadora (o). Os participantes foram identificados pela letra "P" procedido por um número atribuído pela ordem das entrevistas.

o material empírico foi analisado por meio da análise de conteúdo do tipo categorial temática. Nessa perspectiva, procedeu-se à constituição do corpus, por meio das entrevistas; composição das unidades de análise; agregação dos materiais mais relevantes em temas e, finalmente, a análise final do material empírico, sendo organizados em categorias temáticas por: homogeneidade, exaustividade, exclusividade, 


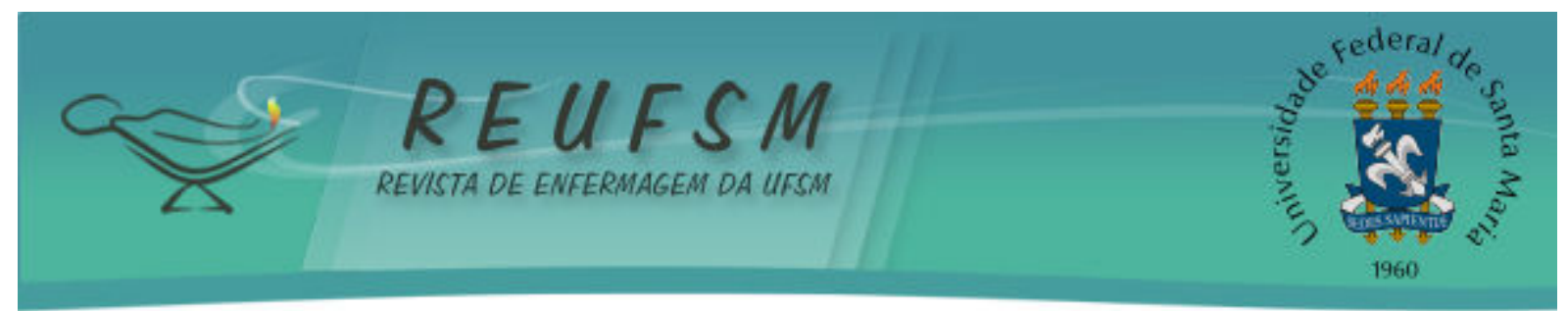

objetividade e adequação ou pertinência. Além disso, utilizou-se a técnica da narrativa que possibilita a confrontação de significados com a literatura pertinente ao tema discutido. $^{12}$

A pesquisa foi desenvolvida de acordo com os aspectos éticos da pesquisa, envolvendo seres humanos recomendados pela resolução n 196/96 do Conselho Nacional de Saúde. 0 projeto foi submetido à apreciação do Comitê de Ética em Pesquisa com Seres Humanos da Universidade Federal da Paraíba (UFPB) que emitiu parecer favorável em 01/07/2010, segundo protocolo $\mathrm{n}^{\circ}$ 264/10.

\section{RESULTADOS E DISCUSSÃO}

As discussões sobre intersetorialidade têm se concentrado ordenadamente na área da gestão pública, a partir do traço constitutivo das políticas setoriais de corte social e no campo da Saúde Coletiva ligado ao processo de implementação do SUS e ao paradigma da promoção da saúde e da integralidade da atenção à saúde. Além disto, a estratégia acerca do princípio do SUS é acionada diante da fragmentação do conhecimento, bem como da ação estatal que "tenta" recompor um resultado sinérgico para o efeito da ação das políticas, tendo em vista, a complexidade das demandas que se colocam neste campo.

Sendo assim, descreveram-se duas grandes categorias que abarcam os principais pontos discursivos: Prática intersetorial de inclusão pelo trabalho e Práticas intersetoriais inclusivas na escola. Ficam evidentes nas duas categorias os principais parceiros na Rede de Saúde Mental que têm favorecido a intersetorialidade e, consequentemente, um maior cuidado em saúde daqueles usuários.

\section{Prática intersetorial de inclusão pelo trabalho}

O discurso da Reforma Psiquiátrica em direção à desinstitucionalização, à inclusão social e à conquista da cidadania, tem induzido os profissionais que atuam nos serviços substitutivos irem em a busca por parceiros intersetoriais. Nesse sentido, este estudo identificou nas falas dos participantes, parcerias que merecem ser divulgadas: o Serviço Nacional de Aprendizagem Industrial (SENAI), através de cursos de qualificação para o trabalho; e, Centro de Referência da Assistência Social (CRAS).

Da parceria com SENAI com o CAPS II - Novos Tempos foram desenvolvidos um Curso de Artefatos em Couros e dois cursos de Panificação e Confeitaria direcionados aos usuários. Esses cursos tinham como finalidade a inserção deles no mercado de trabalho. Esse arranjo intersetorial só foi possível pela iniciativa dos profissionais de saúde do CAPS, e o fato de não haver até então uma articulação entre os dois setores demonstra a fragmentação das ações dos diversos serviços públicos em ações sociais de caráter muito próximo no mesmo território sem uma parceria e fluxo de informações.

Assim, o território tem sido considerado local relevante para a realização das articulações políticas de desenvolvimento urbano e as sociais, devido a presença e participação da comunidade, bem como, por valorizar esta no atendimento aos direitos sociais advindos da demanda comunitária. ${ }^{12}$ Desta forma, a partir da construção deste arranjo intersetorial o curso de Panificação e Confeitaria foi realizado no ano de 2009, no regime de 40 horas semanais, com duração de três meses favorecendo diversos usuários dos CAPS do munícipio. Vale destacar que essa parceria foi estabelecida a partir da inciativa dos profissionais, como se pode observar no relato:

Fomos informados que existiam cursos de Panificação e Confeitaria para portadores de necessidades especiais. Então, procuramos a 


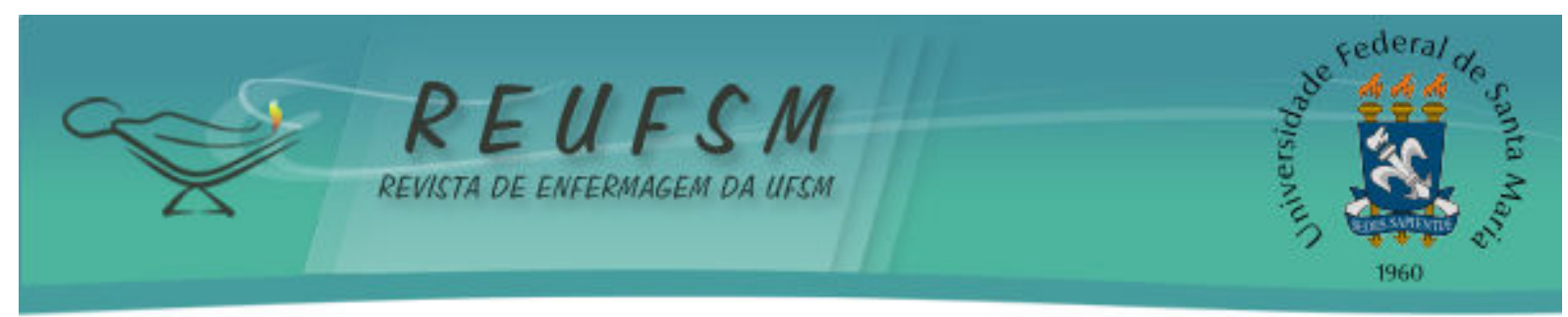

coordenação do SENAI e solicitamos uma oportunidade para encaminharmos nossos usuários para esse curso [...]. (P.09)

O participante revelou que o SENAI disponibilizou vários cursos para que os usuários escolhessem quais preferiam fazer. Entretanto, todos optaram fazer o Curso de Panificação e Confeitaria, por ser considerada uma prática bastante prazerosa e por proporcionar garantia de renda e inclusão ao trabalho.

Nesta primeira oportunidade, foram encaminhados 13 usuários do CAPS II para fazer o curso, e destes, 12 concluíram. No segundo curso oferecido, os profissionais do serviço decidiram incluir na turma usuários e familiares. No entanto, o aproveitamento da oficina para os dois grupos foi bastante diferenciado, enquanto apenas um dos usuários não concluiu o curso por ter se acidentado, nenhum dos quatro familiares matriculados obteve êxito na conclusão.

Os cursos oferecidos pelo SENAI configuraram-se como uma prática inclusiva ao trabalho por ter permitido que os usuários obtivessem uma profissão favorecendo a melhoria da autoestima e da qualidade de vida. Para os profissionais participantes, esta prática de inclusão intersetorial, significou uma possibilidade para a efetivação do exercício da cidadania e para a atenção psicossocial:

[...] acho que por ser um curso que trata de alimentação pode desenvolver algumas habilidades em casa. Alguns já fazem, já confeitam bolo em casa, vendem para os vizinhos. (P.09)

$\mathrm{Na}$ nossa confraternização de natal, o bolo foram eles que fizeram. [...] O SENAI nos proporcionou o forno, o local [...]. O usuário foi com a mãe e mais dois participantes [do curso] e fizeram esse bolo, confeitaram, ficou um bolo lindo. [...] Quando os familiares viram aquela mesa, com tudo confeccionado por eles, você via na cara, o prazer, a satisfação que essa família tinha. (P. 10)

Tem um usuário nosso que está mantendo isso em casa, está fazendo bolo, encomenda de salgados, que de certa forma tem trazido uma renda para casa, [...] porque na verdade não é somente incluir, preparar e capacitar, é fazer com que ele deslanche que ele tenha sua independência financeira e que consiga viver daquilo [...]. (P.06)

As falas acima demonstraram que a participação no curso e o desenvolvimento da atividade como prática profissional têm sensibilizado os familiares dos usuários, mostrando as potencialidades, habilidades, e tornando real a possibilidade de inclusão na sociedade e no mercado de trabalho. Assim, fica evidenciado que um dos desafios das instituições é pôr em prática os princípios da inclusão, formando parcerias que atendam às pessoas portadoras de deficiências.

Para isso, faz-se necessário que as avaliações sociais, psicológicas, educacionais e profissionais, se apoiem em estratégias que busquem superar a prática tecnicista de fragmentação do cuidado, a fim de construir uma abordagem que una conhecimentos e especificidades, favorecendo a articulação e integração de serviços com intuito de buscar soluções para o coletivo. ${ }^{13}$ Cabe destacar, portanto, que os usuários assistidos nos serviços do município pesquisado, embora com um quadro clínico estabilizado, são portadores de 


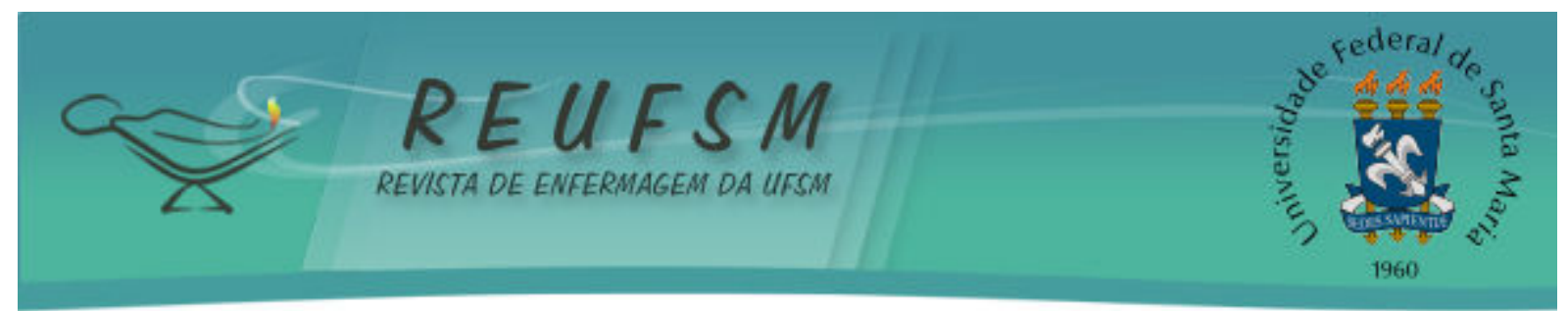

transtornos psíquicos moderados e graves, porém, isso não se configurou num fator dificultador de sua inserção na sociedade.

Salienta-se ainda que a composição desses arranjos intersetoriais na saúde mental tem proporcionado o fortalecimento das relações sociais dos sujeitos em sofrimento psíquico, a partir dos avanços no modelo de cuidado, reintroduzindo-os na sociedade e contando com o apoio de outros atores: famílias, comunidades, profissionais, etc. Nota-se, portanto, a importância da solidificação das redes sociais para reconstrução da dignidade e reconhecimento do sujeito como cidadão, por exemplo, a partir da inclusão dos sujeitos em cursos, atividades remuneradas formais e informais, estando a produção destas ligadas também aos conjuntos sociais. ${ }^{14}$

O Centro Jovem Cidadão e o Centro Cultural também têm efetuado parcerias com os CAPS, principalmente com o CAPS ad ao oferecer vagas em cursos profissionalizantes, como: cabeleireiro, música, violão, capoeira, esportes, piano, artesanato, computação, dentre outros, o que, por meio desta parceria firmada com os serviços da rede de saúde mental do município foi possível à participação de vários usuários para a realização desses cursos.

Outro dispositivo da rede que se tornou um grande parceiro dos CAPS e tem contribuído com a consolidação destas práticas inclusivas é o Centro de Convivência e Cultura. Este serviço está oferecendo cursos, oficinas terapêuticas, arteterapia e atividades de lazer para toda a população e usuários no seu interior, colaborando, assim, com a reabilitação psicossocial. O CRAS tem sido igualmente um dos parceiros dos CAPS, segundo um dos entrevistados.

\section{lá eles realizam palestras para os usuários do CAPS. (P.02)}

Sobre este último, vale destacar que a Política de Assistência Social tem sido uma das mais requisitadas pela política de saúde na composição de arranjos intersetoriais, tendo em vista sua atuação na perspectiva de clinica ampliada sob a ótica de cuidado ao portador de sofrimento e ao seio coletivo e familiar do qual ele faz parte, a partir das ações realizadas pelos CRAS por meio de intervenções na comunidade. Assegurados ainda, a partir dos desfechos de cunho político e social, o direito ao trabalho, o direito de ir e vir, além de uma capacidade emancipatória que segue o caminho contrário ao modelo manicomial/asilar. ${ }^{15}$

Entende-se, portanto, o CRAS como uma estrutura de referência, que atua junto a indivíduos e famílias de modo descentralizado e terrritorializado, incluído na política de assistência social, baseado nos preceitos éticos do SUS, organizado de forma a dispor de estratégias que envolvam ações socioeducativas e de inclusão produtiva. ${ }^{15}$ É neste caso, a partir de ações de inclusão produtiva, que o CRAS contribui junto aos serviços de saúde mental para inclusão social de portadores de sofrimento psíquico.

Os CRAS têm objetivo principal de amparar pessoas e famílias em situação de risco e vulnerabilidade, ao passo que contribui para formação de vínculos e redes de apoio. Neste sentido, trabalhando de forma intersetorial as ações do CRAS buscam a possibilidade de emancipação e instituição de portadores de sofrimento psíquico como sujeito de direitos a partir do protagonismo social. ${ }^{16}$

Desse modo, constatou-se que a reinserção social das pessoas com transtornos mentais na vida pública e coletiva tornou-se essencial, de forma que, suas singularidades possam ser expressas. Sobretudo, a reinserção por meio do trabalho revela avanços inovadores, embora ainda represente um desafio diante do modelo de produção capitalista contemporâneo, que exclui do mundo do trabalho as pessoas consideradas inaptas e/ou improdutivas. ${ }^{17}$ 


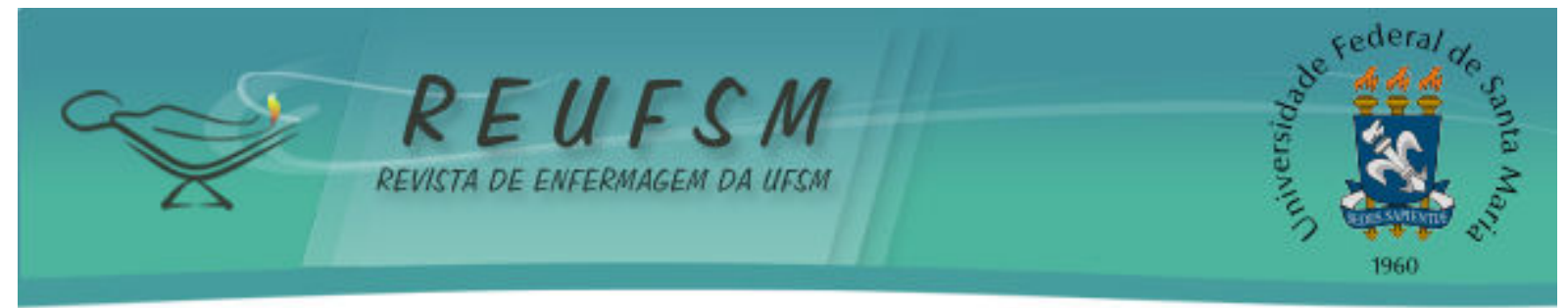

\section{Práticas intersetoriais inclusivas na Escola}

O Projeto Saúde na Escola é uma iniciativa da gestão da saúde mental do município, que tem por objetivo criar parcerias através de formação de redes. Com isso, busca-se diagnosticar precocemente possíveis sinais de sofrimento psíquico que estejam se instalando ainda na infância, preferencialmente crianças menores de seis anos de idade. Tal projeto possibilitou a intervenção precoce de transtornos psíquicos em crianças, exigindo dos profissionais traçarem estratégias de cuidado e acompanhamento dessas.

0 projeto de intervenção precoce está vinculado ao Centro Campinense de Intervenção Precoce também chamado de CAPSinho. Este projeto foi criado através da iniciativa da gestão municipal de saúde mental sob a supervisão e orientação de uma psicanalista do estado da Bahia que já havia iniciado esse trabalho no referido estado. Segundo a coordenadora do projeto no município há quatro anos, o processo de implantação e consolidação enfrentou alguns obstáculos, tendo sido necessários estudos e reuniões com professores, profissionais e gestores municipais.

De acordo com os profissionais responsáveis pela efetivação desta prática, as visitas a creches e escolas municipais, acontecem três vezes por semanas. Trata-se de uma equipe interdisciplinar que se reveza com aproximadamente três profissionais por visita ou de acordo com a necessidade explicitada por cada instituição escolar. Nas falas seguintes, descreveu-se como acontecem essas práticas no cotidiano das escolas e creches da cidade:

[...] a gente vai para perceber as crianças que tem dificuldades gerais [...] não vai só para perceber a criança que tem transtorno, [...] tem que ter um olhar diferente para aquela criança, se ela conversa demais, se ela bate demais. [...] tem que conversar com a família, [...], saber o que é que está acontecendo em casa, se ela está sendo machucada. [...] A gente vai com essa perspectiva, de mostrar ao profissional, que ele precisa de um olhar diferente para que possa fazer intervenções pontuais. A gente faz palestra nas escolas, momentos com os pais, com as crianças [...] leva bichinhos, pintura, [...] para conversar e saber dessa criança, que ela [a professora] me falou do problema. (P. 03)

Levamos sempre alguma coisa que seja interessante para as crianças, comunicamos a escola, automaticamente elas liberam aquele dia, tempo e espaço [...] na escola. E, então nos juntamos a eles, sentamos, brincamos, conversamos, fotografamos, observamos, quem tem determinadas dificuldades, de falar, de olhar, de se entrosar, e de se socializar, conversamos também com a escola, que nos falam das dificuldades com relação aos pais [...]. (P. 11)

[...] as coordenadoras e diretoras, [...] ligam: a gente está com uma criança assim, você poderia fazer uma visita? Se a escola precisa de uma palestra com um neurologista ele vai comigo [...], ele fica a disposição, de acordo com a necessidade. [...] Eu chego às escolas [...] com a equipe, o fonoaudiólogo, psicólogo, fisioterapeuta, depende de cada caso [...]. (P. 03) 


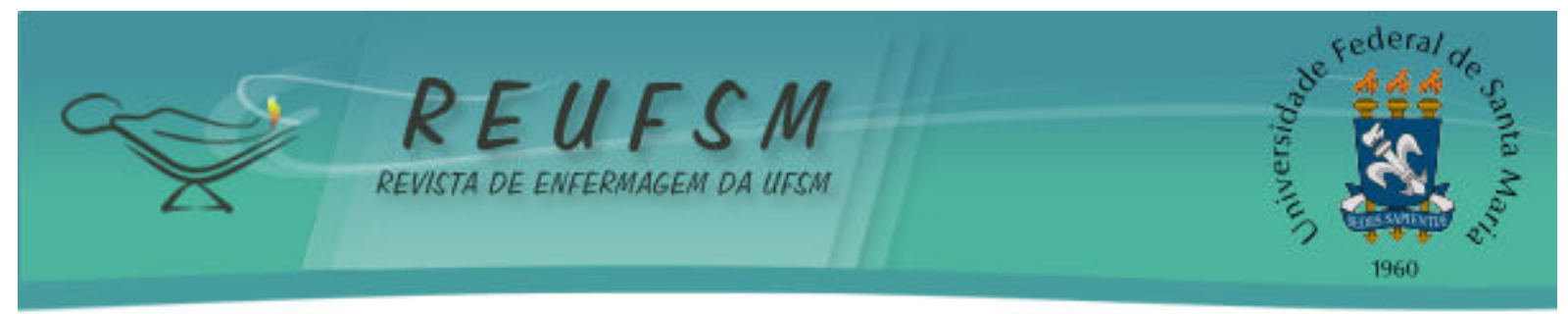

0 projeto de intervenção precoce desenvolvido com estas crianças tem agido de forma preventiva em relação à instalação de problemas psíquicos. Esta prática intersetorial possibilita aos professores mudar o foco da atenção às crianças, bem como, contribuir para que os educadores sintam apoio e confiança nos profissionais dos CAPS, acionando apoio qualificado nos momentos de dificuldade, em prol da melhoria da qualidade de vida das crianças e aumento das possibilidades de inclusão social.

Destaca-se, assim, a importância do cuidado realizado por meio de estratégias preventivas, fundamentadas em ações intersetoriais e multiprofissionais, pois a negligência às demandas clínicas e sociais das crianças e adolescentes pode acarretar e agravar problemas sociais e educacionais durante o desenvolvimento e maturação para fase adulta. ${ }^{18}$ A iniciativa funciona como um mecanismo de aproximar as ações dos serviços públicos para um efeito combinado e no espaço do território de sociabilidade e consequentemente mais próxima das pessoas. A partir desta iniciativa outros serviços são articulados com a Estratégia Saúde da Família (ESF), Centro de Referência de Assistência Social (CRAS), Centro de Referência Especializado de Assistência Social (CREAS), Conselho Tutelar numa perspectiva de superação da lógica fragmentada.

Em alguns momentos, os profissionais, através da realização do exame físico, identificaram sinais de violência contra a criança, sendo necessário intervir:

Teve vários casos que a gente viu que a criança estava caladinha... $E$, quando você começa a conversar com ela, ela está sendo violentada sexualmente em casa, [...] ela está sendo machucada com cigarro, com tudo. (P. 03)

A violência contra a criança é um problema que necessita da intervenção do setor público, a fase de crescimento e desenvolvimento mantém a criança relativamente vulnerável quando exposta a situações de violência, seja ela decorrida dentro do âmbito familiar, escolar ou comunitário. Especificamente, no caso da violência familiar podem ser citadas práticas relacionadas a maus tratos, abuso e abandono ocorridos no ambiente doméstico, geralmente de forma rotineira o que requer uma rede de proteção articulada e fortalecida com intuito de minimizar consequências físicas e danos psicológicos. ${ }^{19}$

A convivência em ambientes desestruturados e a exposição a situações de agressão e violência exigem a organização de ações de caráter intersetorial, por implicar diretamente no desenvolvimento, saúde e capacidade de aprendizado da criança, ocasionado por vezes o acometimento por patologias psíquicas como: déficit de atenção e hiperatividade, depressão, distúrbios do sono, e ansiedade, além do significativo aumento no abandono de atividades escolares. ${ }^{19-20}$

O Estatuto da Criança e Adolescente define no art. 13 que "Os casos de suspeita ou confirmação de maus-tratos contra criança ou adolescente serão obrigatoriamente comunicados ao Conselho Tutelar da respectiva localidade, sem prejuízo de outras providências legais". ${ }^{21: 2}$ Assim, o projeto saúde na escola tornou-se uma prioridade para o município, pois favoreceu ações preventivas e pontuais, importantes diante da atual conjuntura para a consolidação da formação de redes sociais na atenção psicossocial.

Outras ações dentro deste projeto vêm sendo realizadas por parte dos profissionais do CAPSinho:

O saúde na escola já é uma prática intersetorial que a gente faz com os profissionais da educação, [...]. A gente entra em contato também com Justiça, com Conselho Tutelar, com abrigos, a gente mantém esse contato intersetorial. (P. 17) 


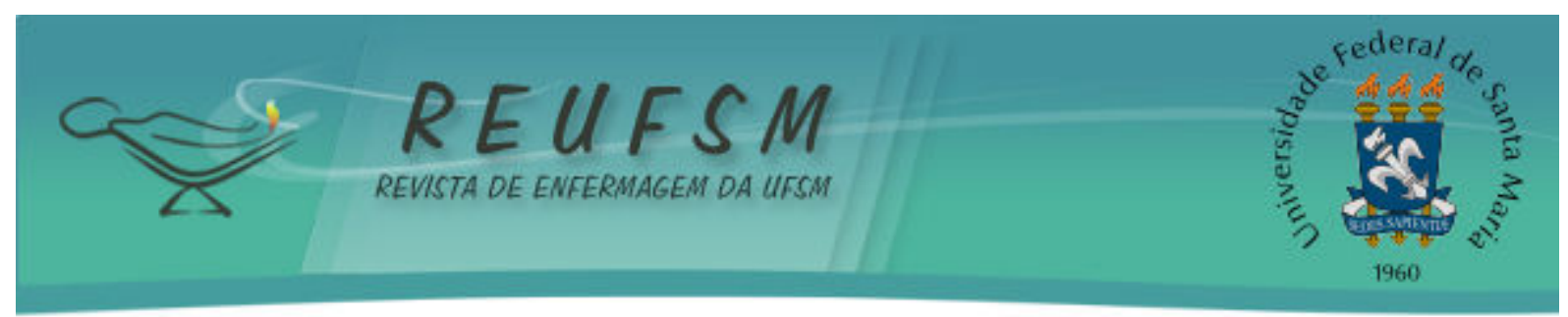

A gente fez um trabalho nos abrigos de Campina Grande, que também tem crianças nas escolas, então tudo está interligado a escola. (P.03)

Os participantes, acima, mostram o envolvimento dos profissionais com outros setores da rede de serviços do município, estabelecidos mediante formação de vínculos e influenciados pelo Projeto de Intervenção Precoce. Além disto, eles sinalizam que, para a resolução dos casos encontrados nas escolas e nos abrigos, buscam apoio da Justiça e do Conselho Tutelar, possibilitando a efetivação da integralidade da assistência, através de ações intersetoriais efetivas.

Portanto, a integralidade, como um princípio que ganha vida na prática, pode ser mobilizada por um efetivo trabalho da equipe multidisciplinar ao potencializar suas próprias capacidades quando pactuam alvos e estratégias. ${ }^{22}$ Nesse entendimento, o CAPS atua junto à família e à sociedade na busca de uma transformação do modelo assistencial vigente e da produção de práticas de integralidade em saúde, com atenção para o fato de que não basta justapor saberes, sendo necessário agir em parceria e complementariedade às demais experiências. ${ }^{23}$

Desse modo, visualiza-se que a rede de cuidado em saúde mental precisa estabelecer vínculos com outros setores, visando à integralidade do cuidado e a consolidação da Reforma Psiquiátrica Brasileira. Entretanto, ressalta-se que essas iniciativas deveriam ser fomentadas pelo poder público de forma articulada, tendo em vista que a estratégia da intersetorialidade aparece como modelo de gestão em diversas políticas, e não serem apenas "executadas" por meio da prática profissional dos trabalhadores da saúde mental.

A estratégia da intersetorialidade tomada enquanto prática profissional se materializa por meio das ações realizadas pelos serviços em parceria com os demais segmentos da rede. No entanto, para se garantir a continuidade dessas ações e consolidála como um trabalho em rede é necessário investimentos em estratégias públicas de gestão como planejamento integrado, instituição de fluxos, protocolos, pactuação de atendimentos entre outras, que viabilizem a manutenção desses arranjos intersetoriais.

\section{CONSIDERAÇÕES FINAIS}

As ações de inclusão social e a estratégia intersetorial tornaram-se um grande desafio político e social no país. Portanto, identificar atividades inclusivas na rede de cuidado de saúde mental a que as políticas se propõem, configurou-se neste estudo uma ação necessária para mostrar que no panorama pesquisado, estas práticas inclusivas acontecem e se constituem como uma ferramenta importante para a Reabilitação Psicossocial, reafirmando a necessidade de expansão desta estratégia para o âmbito nacional.

Os métodos de inclusão utilizados e sinalizados nesse estudo proporcionaram melhorias e progressos na atenção psicossocial, por favorecer articulação com outros setores da sociedade, seja educação, cultura, a economia e a formação de redes sociais. São estratégias que se consolidam e favorecem integração na rede de cuidados, bem como, capacitação dos profissionais para uma atuação mais efetiva e eficaz, promovendo elos intersetoriais que se consolidam e promovem a inclusão dos usuários em seu território.

Considerando essa perspectiva, as ações intersetoriais de cuidado funcionaram no sentido de valorizar a formação de vínculos afetivos entre usuários, família e trabalhadores do CAPS e a rede de serviços que dá suporte a saúde mental produzindo uma "nova" subjetividade ligada aos processos. Identificando também, que os profissionais do CAPS 


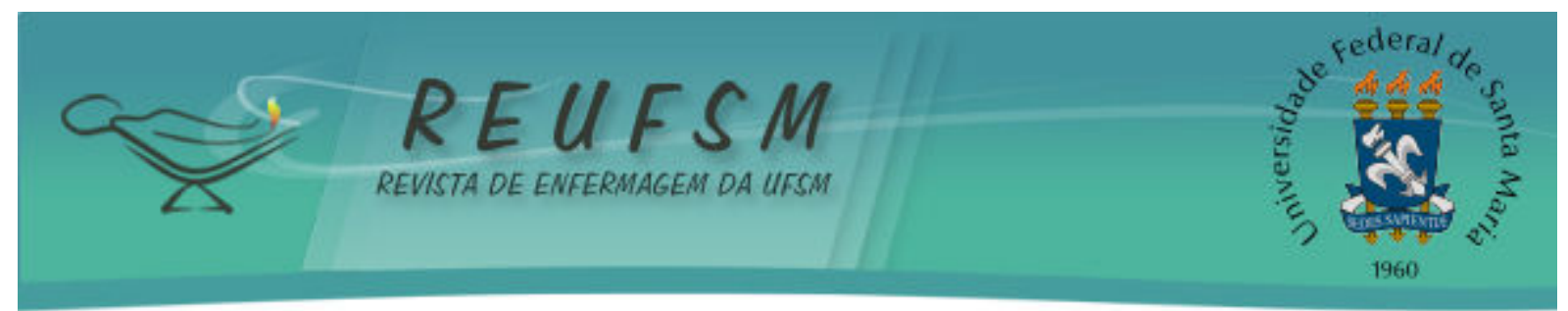

cumprem seu papel no contexto da Reforma Psiquiátrica, promovendo saúde mental a partir da inserção social, afastando-se do tradicional modelo biomédico pautado no modelo hospitalocêntrico.

Contudo, salienta-se que a estratégia da intersetorialidade orientada para a inclusão social deve ser construída a partir de um esforço coletivo com ressonância nos processos de gestão das políticas sociais na criação de um novo espaço de relações, acarretando em ações efetivas e inovadoras na rede de saúde mental.

Observa-se com este estudo que muito se tem a avançar no tocante a intersetorialidade e a inclusão de pessoas em sofrimento psíquico na sociedade, e iniciativas como as citadas nesta pesquisa, alavancam ideias para construção de uma nova página da Reforma Psiquiátrica, que se consolida a cada dia como uma política estratégica para reordenação do cuidado em saúde mental.

Percebeu-se como limitação referente aos resultados deste estudo, as relacionadas ao método, a partir da pesquisa qualitativa e amostragem intencional, envolvendo somente os profissionais que realizam práticas intersetoriais na rede de saúde mental, que não permite a generalização à população global. No entanto, buscou-se contribuir para divulgar e ratificar a importância da intersetorialidade como estratégia para a reabilitação psicossocial dos usuários.

\section{REFERÊNCIAS}

1. Brasil. Ministério da Saúde. Portaria $n^{\circ} 3.088$, de 23 de dezembro de 2011. Institui a Rede de Atenção Psicossocial para pessoas com sofrimento ou transtorno mental e com necessidades decorrentes do uso de crack, álcool e outras drogas, no âmbito do Sistema Único de Saúde [Internet]. [acesso em 2014 ago 26]. Disponível em: http: / / www.saude.mg.gov.br/images/documentos/Portaria\%20do\%20Ministerio\%20da\%20Sa ude\%20GM\%20N\%203088\%202011\%202702.pdf.

2. Bezarra Júnior B. Desafios da reforma psiquiátrica no Brasil. Physis. 2007;17(2):243-50.

3. Hirdes A. A reforma psiquiátrica no Brasil: uma (re)visão. Ciênc Saúde Coletiva. 2009;14(1):297-305.

4. Yasui S. Rupturas e encontros: desafios da reforma psiquiátrica brasileira. Rio de Janeiro(RJ): Fiocruz; 2010.

5. Amarante $P$, coordenador. Loucos pela vida: a trajetória da reforma psiquiátrica no Brasil. $2^{\mathrm{a}}$ ed, $5^{\mathrm{a}}$ reimp. Rio de Janeiro(RJ): Fiocruz; 2010.

6. Vargas LA, Oliveira TFV, Garbois JA. 0 direito à saúde e ao meio ambiente em tempos de exclusão social. Rev Latinoam Enferm [Internet]. 2007 [acesso em $2014 \mathrm{abr} 28$ ];15(N Esp):850-6. Disponível em: http://www.scielo.br/pdf/rlae/v15nspe/pt_20.pdf. Doi: 10.1590/S0104-11692007000700021.

7. Amarante P. Saúde mental e atenção psicossocial. $2^{a}$ ed, rev e ampl. Rio de Janeiro(RJ): Fiocruz; 2008.

8. Brasil. Ministério da Saúde. Secretaria de Atenção à Saúde. Coordenação Geral de Saúde Mental. Reforma psiquiátrica e política de saúde mental no Brasil: Conferência Regional de Reforma dos Serviços de Saúde Mental: 15 anos depois de Caracas. Brasília: OPAS; 2005.

9. Brasil. Ministério da Saúde. Saúde mental no SUS: os Centros de Atenção Psicossocial. Brasília: Ministério da Saúde; 2004. (Série F. Comunicação e Educação em Saúde). 


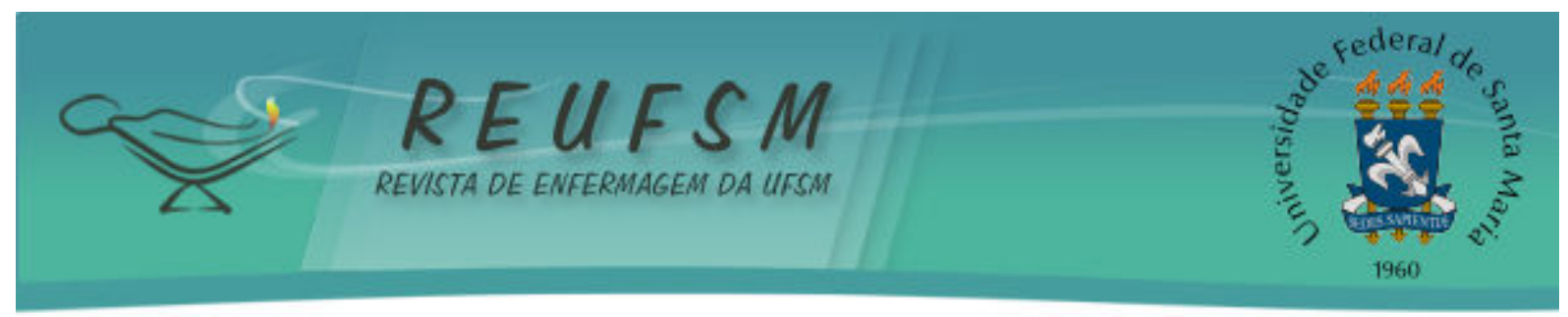

10. Rede Unida. Intersetorialidade [Internet]. 2004 [acesso em 2009 dez 9 dez]. Disponível em:

http://www.saude.rio.rj.gov.br/cgi/public/cgilua.exe/web/templates/htm/v2/view.htm? editionsectionid=30\&infoid=2516.

11. Bardin L. Análise de conteúdo. Lisboa: Editora 70; 2009.

12. Andrade LOM. A saúde e o dilema da intersetorialidade. São Paulo(SP): Hucitec; 2006.

13. Boccardo ACS, Zane FC, Rodrigues S, Mângia EF. O projeto terapêutico singular como estratégia de organização do cuidado nos serviços de saúde mental. Rev Ter Ocup Univ [Internet]. 2011 [acesso em 2014 jul 25];22(1):85-92. Disponível em: http://www.revistas.usp.br/rto/article/view/14124/15942.

14. Fontes BASM. Redes sociais e saúde: sobre a formação de redes de apoio social no cotidiano de portadores de transtorno mental. Política \& Trabalho [Internet]. 2007 [acesso em 2014 jul 25];26:87104. Disponível em: http://www.nucleodecidadania.org/nucleo/extra/2007_07_16_06_10_51.pdf.

15. Nascimento MAN, Carvalho A. O processo de descentralização e territorialização de serviços de saúde mental em CRAS. Rev Psicologia UNESP. 2009;8(1):32-47.

16. Toniato JS, Tavares T, Pessini MA. As contribuições do centro de referência de assistência social (CRAS) às famílias em vulnerabilidade/risco social. Akrópolis. 2010;18(4):247-61.

17. Rodrigues RC, Marinho TPC, Amorim P. Reforma psiquiátrica e inclusão social pelo trabalho. Ciênc Saúde Coletiva. 2010;15 Supl 1:1615-25.

18. Arrué AM, Neves ET, Terra MG, Magnago TSBS, Jantsch LB, Pieszak GM, et al. Crianças/adolescentes com necessidades especiais de saúde em centro de atenção psicossocial. Rev Enferm UFSM [Internet]. 2013 [acesso em 2014 abr 28];3(2):227-37. Disponível em: http://cascavel.ufsm.br/revistas/ojs2.2.2/index.php/reufsm/article/view/7827doi:10.5902/217976927827.

19. Assis SG, Avanci JQ, Pesce RP, Ximenes LF. Situações de crianças e adolescentes brasileiros em relação à saúde mental e à violência. Ciênc Saúde Coletiva. 2009;14(2):349-61.

20. Feitosa HN, Ricou M, Rego S, Nunes R. A saúde mental das crianças e dos adolescentes: considerações epidemiológicas, assistenciais e bioéticas. Rev Bioét. 2011;19(1):259-75.

21. Brasil. Ministério da Saúde. Estatuto da Criança e do Adolescente. 3 ed, $2^{a}$ reimp. Brasília: Ministério da Saúde; 2008. (Série E. Legislação de Saúde).

22. Silva RVGO, Ramos FRS. Integralidade em saúde: revisão de literatura. Ciênc Cuid Saúde. 2010;9(3):593-601.

23. Alvarez SQ, Gomes GC, Xavier DM. Assistance received in a psychosocial care center: perception of drug users and family. Rev Enferm UFPE online. 2012;6(8):1805-11.

Data de recebimento: $17 / 04 / 2014$

Data de aceite: $27 / 08 / 2014$

Autor Correspondente: Elisângela Braga de Azevedo.

Endereço Postal: Pedro Soares da Silva, 55. Itararé. Campina Grande/PB/Brasil. CEP: 58411-150.

Email: elisaaz@terra.com.br 